\title{
Sotos syndrome: a study of the diagnostic criteria and natural history
}

\author{
T R P Cole, H E Hughes
}

\begin{abstract}
Seventy-nine patients with a provisional diagnosis of Sotos syndrome were clinically assessed, and their photographs between the ages of 1 and 6 years evaluated. These photographs, together with photographs of first degree relatives, also at ages 1 to 6 years, were reviewed by four clinical geneticists. Forty-one probands (but no first degree relatives) were identified in whom the facial gestalt was thought to be characteristic of Sotos syndrome. Comparison of anthropometric measurements, bone age, and developmental delay in these 41 probands showed marked differences between them and the remaining 38 probands, and allowed the formulation of guidelines for the diagnosis of Sotos syndrome. Length was identified as the most significantly increased prenatal parameter. In childhood occipitofrontal head circumference (OFC), height, and weight were all increased. OFC remained above the 97 th centile in all but one case throughout childhood and adulthood, whereas height and weight had a tendency to return towards the mean. This 'normalisation' was more pronounced in females and was probably related to their early puberty. Early developmental delay and an advanced bone age, seen in $100 \%$ and $84 \%$ respectively of study cases, may be invariable in Sotos syndrome, but selection bias and limited data prevented confirmation of this supposition. The authors suggest that facial gestalt, growth pattern, bone age, and developmental delay are the major diagnostic criteria. Using these criteria, no affected first degree relatives were identified. There were few long term medical complications in the probands, but behavioural difficulties caused considerable parental concern.
\end{abstract}

Genetics, University Hospital of Wales, Heath Park, Cardiff, CF4 4XW, UK. T R P Cole $H$ E Hughes

Correspondence to Dr Cole, Clinical Genetics Unit, Birmingham Maternity Hospital, Birmingham B15 2TG, UK

Received 12 May 1993. Revised version accepted for publication 6 July 1993.

( $($ Med Genet 1994;31:20-32)

In 1964 Sotos et al described five children with overgrowth and characteristic facies although the present authors suspect the patient described by Schlesinger ${ }^{2}$ in 1931 may have been the first reported. The cases of Sotos et $a l^{l}$ have formed the basis of a condition known as cerebral gigantism or Sotos syndrome but, despite the description of over 200 further cases, there still remain fundamental unanswered questions about the condition.

At the centre of the problem is the obvious lack of specificity and the unknown sensitivity of the inferred diagnostic features typically listed as characteristic facies, pre- and postnatal overgrowth, advanced bone age, and developmental delay with a non-progressive neurological disorder. On reviewing published reports on Sotos syndrome, the problem of specificity soon becomes apparent; there are many large, dysmorphic children with varying degrees of clumsiness and delay. Some of these children appear to fit into other well recognised phenotypes listed in table $1 .^{3-21}$ However, many cases do not seem to fit into either Sotos syndrome or these other recognised overgrowth syndromes. Assessment of the sensitivity of the clinical features requires screening with a pathognomonic marker which is not as yet available.

In order to address the problem of specificity, the authors have identified a group of 79 patients with the provisional diagnosis of Sotos syndrome. The facial gestalt of these patients has been critically reviewed and a group of 41 patients, very similar to one another, has been identified. The growth pat-

Table 1 Conditions in which generalised or regional overgrowth may be present.

Weaver-Smith syndrome ${ }^{34}$

Marshall-Smith syndrome $e^{56}$

Simpson-Golabi-Behmel syndrome ${ }^{78}$

Ruvalcaba-Myhre-Sm

Perlman syndrome ${ }^{1112}$ iedemann syndrome ${ }^{1314}$

Beckwith-Wiedemann
SanFilippo syndrome 15

SanFilippo syndrom
Proteus syndrome

Proteus syndrome
Marfan syndrome 18

Marfan syndrome
Klinefelter syndrome

Klinefelter syndrome
Trisomy 8 mosaicism

Trisomy 8 mosaicism $2^{21}$
Fragile $X$ syndrome
Table 2 Protocol for categorising patients.

\begin{tabular}{ll}
\hline $\begin{array}{l}\text { First assessment: } \\
\text { facial gestalt alone }\end{array}$ & $\begin{array}{l}\text { Second assessment: } \\
\text { facial gestalt plus data* }\end{array}$ \\
\hline Group 1 & Group 1 \\
Definitely Sotos & Definitely Sotos \\
Group 2 & Group 2 \\
Possibly Sotos & Possibly Sotos \\
Group 3 & Group 3 \\
Definitely not Sotos & Definitely not Sotos
\end{tabular}

* Data provided on height, head circumference, developmental milestones, and bone age. 
Table 3 Patient categories.

\begin{tabular}{lllll}
\hline & $\begin{array}{c}\text { Scoring on } \\
\text { gestalt } \\
\text { alone }\end{array}$ & \multicolumn{3}{c}{ Rescored with data* to } \\
\cline { 3 - 5 } & 41 & Group 1 & Group 2 & Group 3 \\
\hline Group 1 & 16 & 40 & 1 & - \\
Group 2 & 22 & - & 7 & 9 \\
Group 3 & 79 & 40 & 3 & 19 \\
Total & & 11 & 28 \\
\hline
\end{tabular}

* Data provided on height, head circumference, developmental milestones, and bone age.
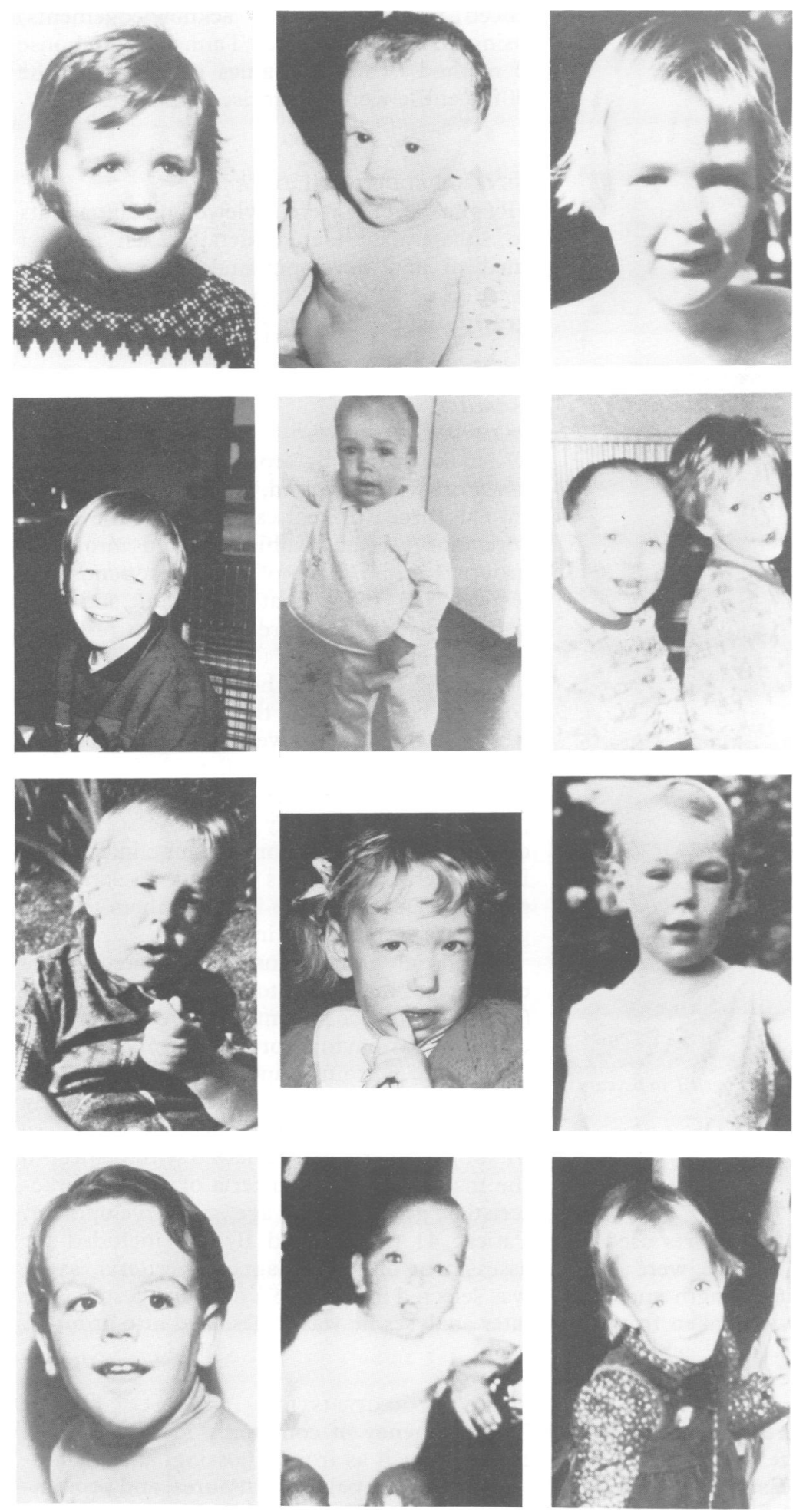

Figure $1 \mathrm{~A}$ From left to right, facial photographs of cases 1 to 12 aged 1 to 6 years. terns and bone ages in these 41 subjects showed a striking consistency which was not found in the 38 excluded cases.

These findings are presented below and their possible significance as diagnostic criteria considered. In addition, the natural history, recurrence risks, and possible aetiology of Sotos syndrome are discussed.

\section{Methods}

Referrals were sought only from groups who were most likely to be in touch with patients affected with Sotos syndrome. These groups included Departments of Medical Genetics throughout the United Kingdom, the Welsh Paediatric Association, selected paediatric neurologists, and the Sotos syndrome parent support group.

One hundred and one families who had a child previously diagnosed as having Sotos syndrome were contacted by post and asked if they would take part in a clinical study. (The authors considered all diagnoses as provisional until confirmed by the protocol described below.) Of these only two specifically requested not to be included and a further seven families did not reply. Seventy-nine families were personally assessed by one of the authors (TC), 77 at home and two in hospital. The remaining 13 subjects were either assessed by a colleague undertaking a similar study (six cases) and were excluded from this study or were inaccessible because of practical problems (seven cases).

Each affected child was examined and a chronological series of photographs obtained. All available sibs and parents were assessed in the same fashion. Subsequently, hand $x$ rays were obtained for bone age assessment and metacarpophalangeal profiles (MCPP) from probands and from some parents for MCPP analysis only.

Each patient was 'categorised' by the authors into one of the groups listed in table 2 . As the authors' categorisation was not undertaken before discussion in every case, a high level of agreement was not unexpected and therefore these 'scores' were considered as one. In an effort to confirm the reproducibility of our classification, two clinical geneticists with particular experience in the field of dysmorphology (DD and ET, see acknowledgements) were asked to review photographs provided of 78 probands (one family refused permission for photographs) aged between 1 and 6 years. In addition, photographs taken between the ages of 1 and 6 years of 22 first degree relatives were included in this review without differentiation from the index cases. The geneticists were asked to 'score' each person to one of the three categories listed in table 2, on facial gestalt alone initially, and then all photographs were 'scored' again but on this occasion additional data on growth, bone age, and development were provided. In order to minimise bias their previous scores (photo alone) were not made available for comparison.

The standards used for growth, development, and bone age are listed below. 

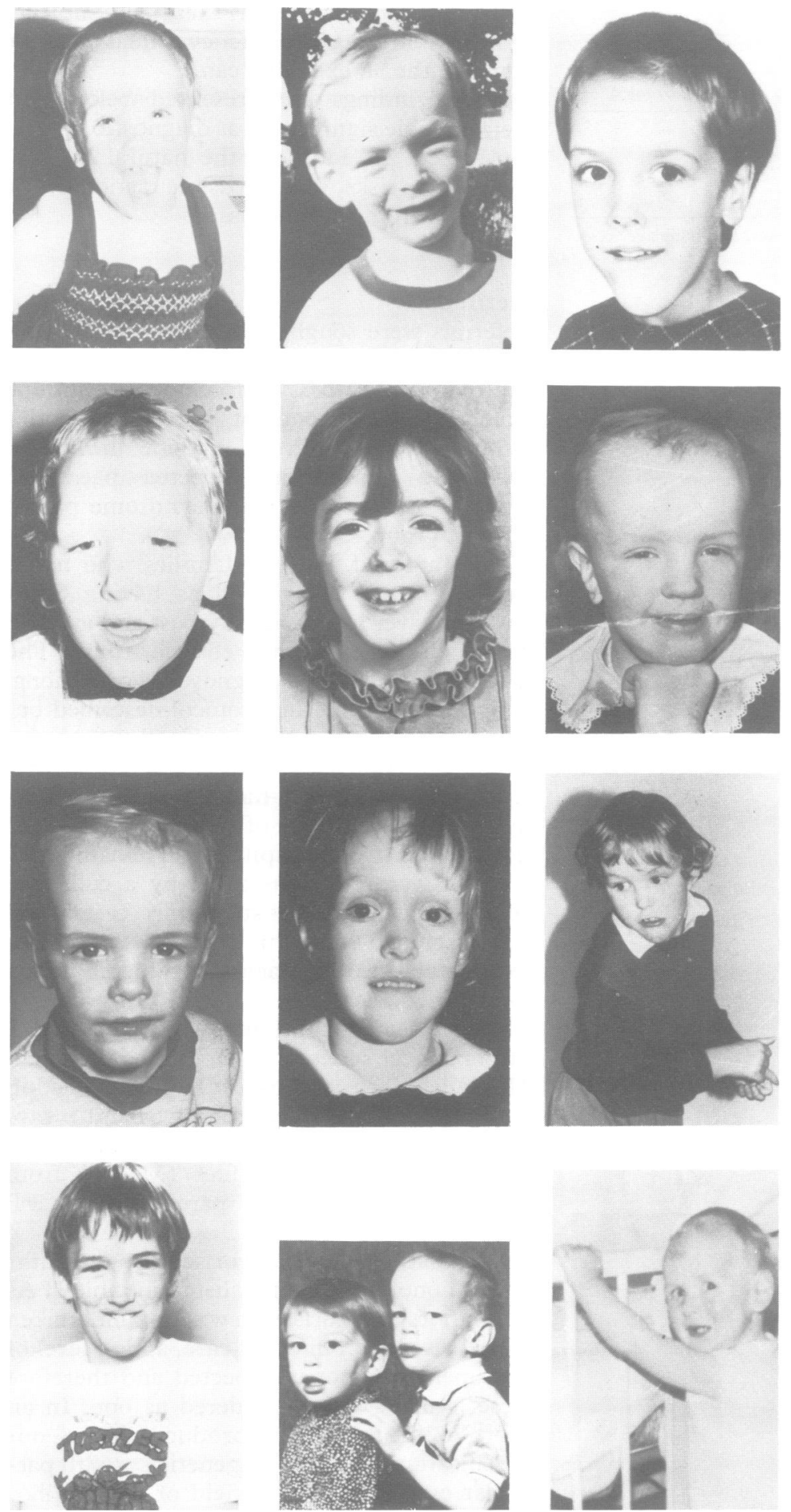

Figure 1B From left to right, facial photographs of cases 13 to 24 aged 1 to 6 years.

GROWTH

Mean and standard deviation charts used for children after 3 months of age were those compiled by Tanner. ${ }^{22}$ Birth length and head circumference standards were taken from the data of Gairdner and Pearson ${ }^{23}$ while birth weight controls were taken from the data of Keen and Pearse. ${ }^{24}$ Increased height and head circumferences (OFC) were defined as a minimum of two consecutive height measurements, $>97$ th centile, at least a year apart, and an OFC $>98$ th centile at the time of assessment by one of the authors (TC).

\section{DEVELOPMENTAL DELAY}

Developmental delay was accepted if at least one of the following was positive. (1) The primary referral was made because of 'identified' developmental delay. (2) Formal developmental assessment was outside the normal range, as recorded in hospital charts. (3) Motor and early verbal milestones, as given by the parents and confirmed in the medical notes, were outside the 90 th centile. ${ }^{25}$

\section{BONE AGE}

All bone ages were assessed by a single experienced person ( $J R$, see acknowledgements) using a computer assisted Tanner-Whitehouse 2 method (TW2). ${ }^{26}$ Values greater than the 90th centile were categorised as advanced.

\section{GENERAL ADDITIONAL DATA}

Hospital records were reviewed on all patients to substantiate factual details such as past medical and developmental histories. They were used also as a source of longitudinal growth data.

\section{Results}

\section{PATIENT CATEGORIES}

When the proband's 'scores' given by the three assessors were reviewed, no subject was scored into all three different categories by the assessors, nor was any subject scored into both groups 1 and 3. Each of the 78 probands was 'categorised' twice (that is, without and with data) by each of the three geneticists resulting in a total of 468 'scores' $(78 \times 2 \times 3)$. Eighty-six percent $(404 / 468)$ of these scores were concordant between the three. In those cases where all three scores were not concordant the majority view was accepted.

None of the 22 first degree relatives was placed in group 1 by any of the assessors, when considered either with or without clinical data. Eighty percent of scores placed the relatives in group 3. Details of the final numbers in each group are summarised in table 3 .

On facial gestalt alone, 41 patients were classified as definite Sotos syndrome (group 1) (fig 1A-F). These patients had previously been diagnosed as having Sotos syndrome between the ages of 3 months and 11 years (mean age 26.6 months) and were assessed for the study by TC between 18 months and 23 years. These 41 subjects were then reviewed with respect to the major diagnostic criteria of facial characteristics, growth, bone age, and development. Patient 41 (fig 2A and B) was included for assessment of these diagnostic criteria, as he was selected into group 1 on facial gestalt. For later analyses he was reclassified into group 2 .

\section{FACIAL CHARACTERISTICS}

The frequency of commonly identified facial features, such as frontal bossing, antimongoloid slant of the palpebral fissures, and prominent jaw, are listed in table 4. However, the most striking feature of the face in Sotos 

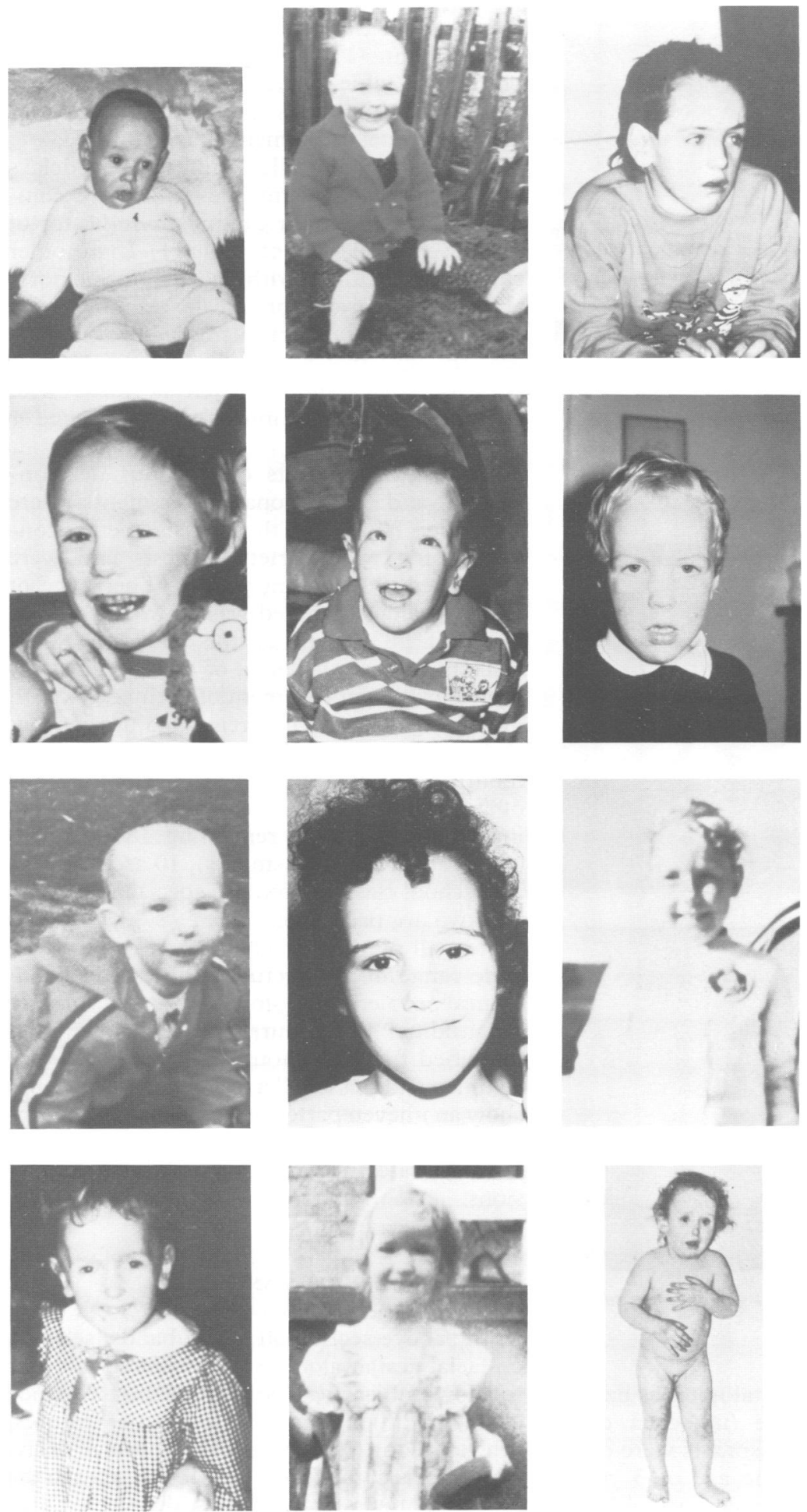

Figure 1C From left to right, facial photographs of cases 25 to 36 aged 1 to 6 years.

syndrome is the overall gestalt (fig $1 \mathrm{~A}-\mathrm{F}$ ), but several additional characteristics merit specific comment. Sparseness of hair, in particular involving the frontoparietal region, is an almost constant finding and this feature tends to accentuate the large bossed forehead. The nares are usually anteverted and the nose is frequently erythematous. This colouration is also commonly seen on the cheeks and perioral region. The face gradually lengthens with time and the jaw becomes more prominent although not necessarily prognathic (fig $1 \mathrm{G}$ ), which results in a facial shape similar to the outline of an inverted pear.
The skull is not only macrocephalic but also dolichocephalic. An interesting result of the shape of the skull and face is the almost universal clinical impression of hypertelorism which is often not borne out by measurement (table 5).

\section{GROWTH}

Height, weight, and OFC measurements at birth and at the time of diagnosis are summarised in tables 6,7 , and 8 . At birth, length was likely to be more increased than weight (tables 6 and 8). Birth head circumference also was raised above the 97 th centile in almost half the children (table 6) and frequently showed a rapid increase during the neonatal period, probably following the resolution of moulding caused during delivery. Within 12 months virtually all OFC values are above the 97th centile (fig 3).

Throughout childhood and early adolescence, the height frequently remained at or above the 97th centile and, at least until the time of diagnosis, was usually more significantly increased than weight (figs $4 \mathrm{~A}, \mathrm{~B}$, and $5 A, B$, table 8). Thirty-seven out of 39 children fulfilled the criteria for increased height given above (in two cases there were insufficient data to apply these criteria). However, final height may well be below the 97th centile, particularly in females, in whom the growth pattern correlated well with the presence of advanced bone age and early puberty. Three out of four postmenarchal adult females have achieved final heights between the 50th and 90th centiles; menarche in all three was before 11 years 3 months ( $<10$ th centile). In the study at present there are seven males over the age of 10 years and preliminary data identify passage of pubertal markers later than the 50th centile in four out of five cases, with one delayed beyond the 90th centile. In only one case out of the seven has puberty occurred before the 10th centile. Two of the seven boys are still too young to assess timing of puberty.

\section{BONE AGE}

Childhood $x$ rays were available in 37 cases; of these, $31(84 \%)$ showed a bone age advanced to or beyond the 90th centile (table 9). Of the three children with bone ages between the 75 th and 90th centile (all values only just below the 90 th centile), two were over the age of 12 years at the time of assessment. Of the three remaining cases (bone age 50th to 75th centile), in one the assessment was made at the age of 11 years and this patient had documentation of several earlier, but unavailable films, showing bone ages in excess of the 97th centile; one was still felt to have a phenotype consistent with Sotos syndrome (case 27), but the last was 'rescored' into group 2 despite his characteristic gestalt (case 41). This latter subject was the only one of the 41 probands identified as 'typical Sotos syndrome' (group 1) on facial gestalt alone, and subsequently reclassified into group 2 . Of particular interest is that 10 of the patients with a bone age $>90$ th centile had previously 

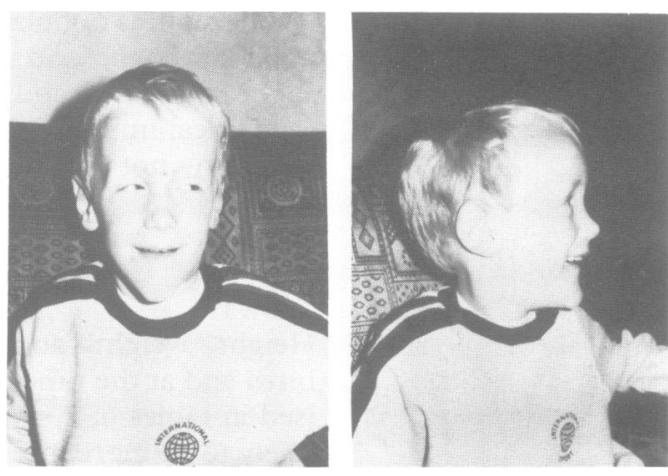

Figure 1D Case 37 aged 6; AP and profile aspects. (Permission for publication of photographs of cases 38 to 40 refused.)
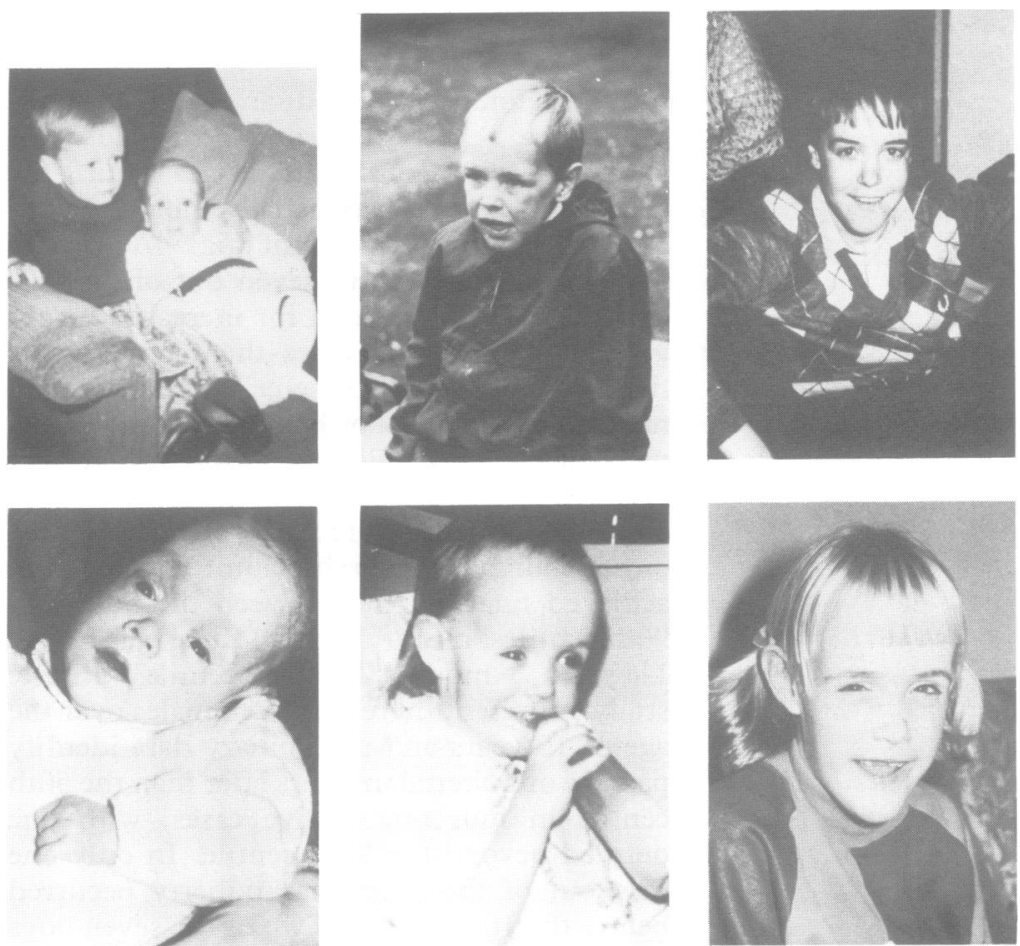

Figure $1 E$ Upper row: case 6 at ages 3 months, 7 years, and 14 years. Lower row: case 12 at ages 1 month, 18 months, and 7 years.

been reported in their hospital notes as having a bone age <90th centile (in seven cases $<75$ th centile). These assessments were commonly performed before the age of 3 years. Four of the 10 early films were available for review and when reassessed by us using the TW2 method, all had bone ages in excess of the 90 th centile.

DEVELOPMENTAL DELAY

Despite access to patient records, developmental delay proved to be the most difficult feature to assess reliably, partly because of the lack of objective data and partly because of the wide variety of assessments used. Also, it is important to remember that many of the patients had originally come to medical attention because of developmental delay and consequently our cohort is likely to be biased for this particular feature. For the current study, details about each of the three following areas were sought: (1) present or final educational placement (table 10), (2) timing of early motor and verbal milestones (table 11), (3) previous developmental assessment if available.

From parental recall, significant early delays in speech and performance skills were common, although a poor prognostic indicator of future school placement (table 11). In the older children difficulties with short term memory, abstract ideas, and practical reasoning were felt to cause greater problems. However, parents thought that numeracy was the weakest area in older children, even in those with overall IQ scores well into the average range or above.

In 23 cases, results of previous developmental and educational assessments were available. However, these assessments consisted of a wide variety of tests and were performed by different people. The range of $\mathrm{DQ} / \mathrm{IQ}$ values obtained was 40 to 129 , with a mean of 78 . In 10 of the 23 cases, serial assessments are available; of these, eight children showed improvement of their scores with increasing ages and one remained unchanged. Only one showed any decline, from 71 at 12 months to 55 at 23 months; this alteration was of a degree that might be explained by testing inaccuracies. Of the remaining 18 probands (without formal assessments), 10 are in a regular school class, six require special education, and two are preschool.

A small pilot study has already confirmed a wide range of intellectual abilities and behavioural problems in Sotos syndrome. ${ }^{27} \mathrm{~A}$ larger longitudinal study, currently under way, has identified that behavioural problems are very common and that intellectual abilities frequently show an uneven pattern (Finegan $e t$ al, unpublished data). This combination can easily lead to inaccurate assessments and overall impressions.

\section{ADDITIONAL FEATURES AND MEDICAL} COMPLICATIONS

In the above section all 41 probands, selected on facial gestalt alone, are considered in order to allow unbiased assessment of the frequency of the additional major diagnostic features, growth, bone age, and developmental delay. The results in the following section refer to the final 40 patients diagnosed as 'definitely Sotos syndrome' (group 1, table 3 ) after reassessment including the three major criteria above.

OBSTETRIC AND NEONATAL

Of the 40 probands, $75 \%$ were born by normal vaginal delivery $(34 / 40), 7 \cdot 5 \%(3 / 40)$ by forceps assisted vaginal delivery, and $7 \cdot 5 \%(3 / 40)$ by caesarean section. The indications for caesarean section were oblique lie, failed induction at 42 weeks, and an emergency section for locked twins with a cord prolapse. Gestation at delivery ranged from 28 to 43 weeks, with a mean of 39 weeks. Thirty-three deliveries were after 37 weeks.

In the neonatal period, features of particular 

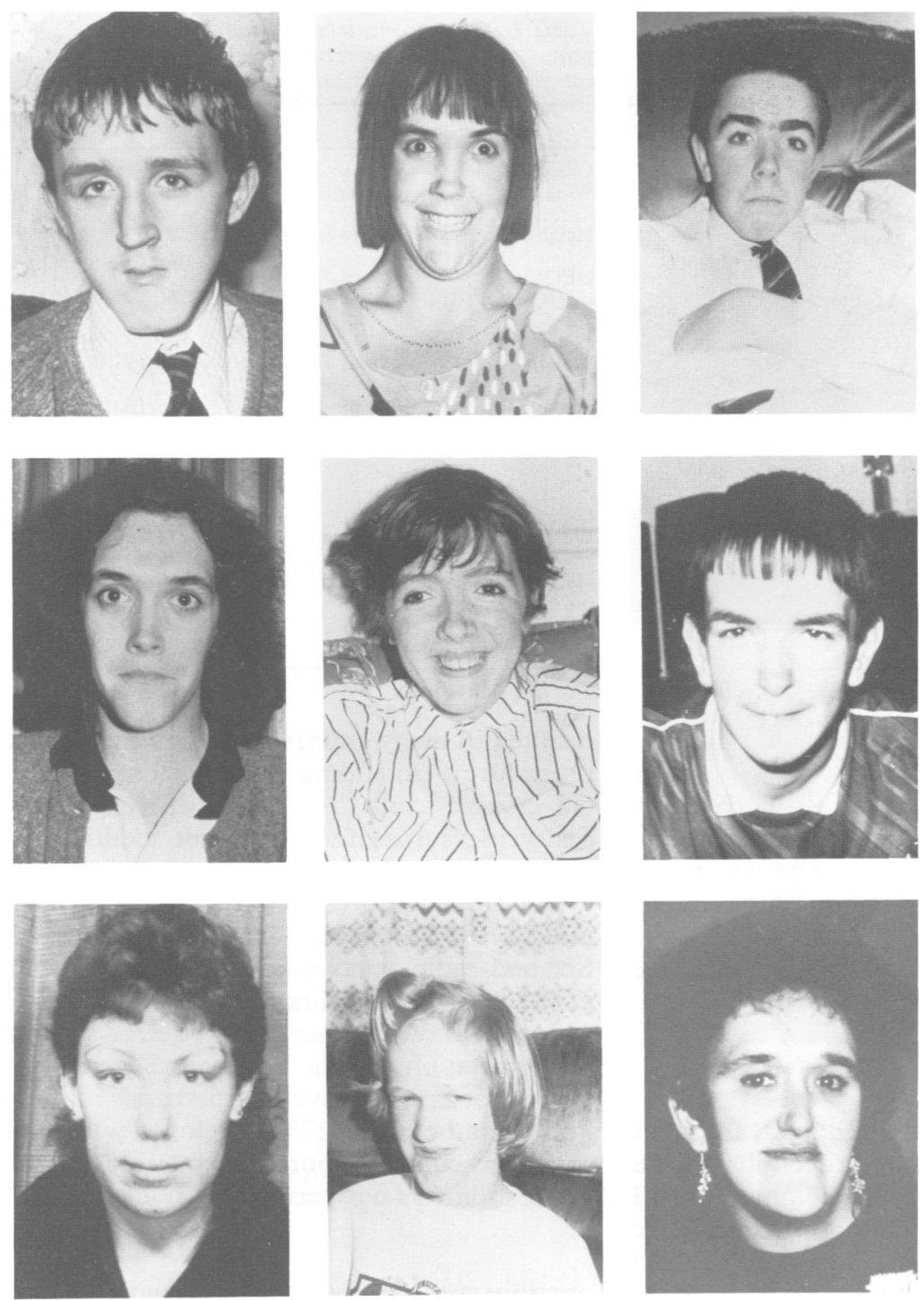

Figure 1F Adolescent/adult photographs of cases 1, 5, 10, 15, 17, 26, 33, 35, and 36 .

note included poor feeding and jaundice. Although absolute measurements of serum bilirubin were not always available, $90 \%$ of parents recalled jaundice being present and in $62 \%$ of cases either phototherapy or exchange transfusion was required. In only one case was a proven cause found, this being the presence of anti-e antibodies. Similarly, feeding difficult-

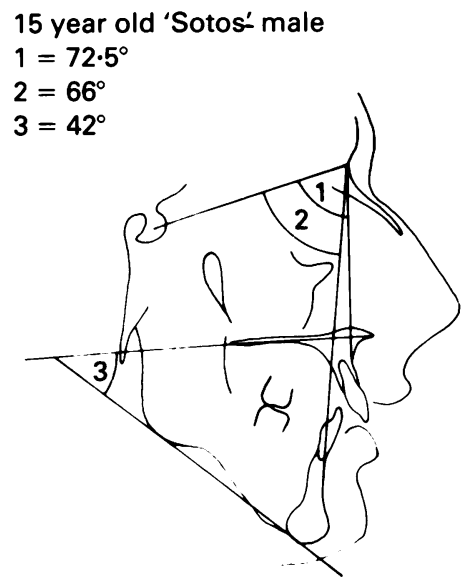

$$
\begin{aligned}
& 15 \text { year old 'normal' male } \\
& \begin{array}{l}
1=82 \cdot 5^{\circ} \\
2=81^{\circ} \\
3=28 \cdot 5^{\circ}
\end{array}
\end{aligned}
$$

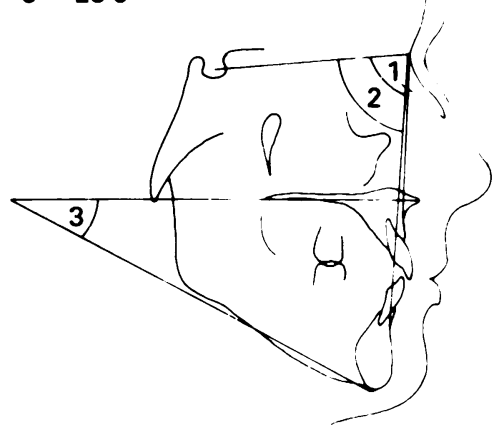

Figure $1 G$ Lateral cephalometric studies in a 15 year old child with Sotos syndrome and unaffected child for comparison.
Table 4 Facial characteristics.

\begin{tabular}{ll}
\hline Frontal bossing & $97 \cdot 5 \%$ \\
High hairline & $97 \cdot 5 \%$ \\
Prominent jaw & $95 \%$ \\
Palpebral fissures, antimongoloid slant & $90 \%$ \\
Facial flushing & $85 \%$ \\
Dolichocephaly & $80 \%$ \\
High palate & $70 \%$ \\
\hline
\end{tabular}

ies were unexpectedly common; $40 \%$ of children required tube feeding including $25 \%$ of all term babies.

Neonatal hypotonia was commonly recorded and may account for the high frequency of feeding problems in our series and respiratory problems in other published reports. Unfortunately, tone is not specifically documented in all neonatal notes, but hypotonia was a feature in $87.5 \%$ of cases during early childhood.

\section{NEUROLOGICAL FINDINGS}

Although there was a tendency for tone to improve with age many children had a persistent hypotonic posture and gait. Paradoxically even in the presence of hypotonia, brisk reflexes, particularly involving the legs, were common $(78 \%, 28 / 36)$, and these were often associated with several beats of clonus. Extensor plantar reflexes were documented in three cases. These findings, although subtle, had usually been identified by several independent observers. Similar findings have been reported by Ginter and Scott. ${ }^{28}$

Clumsiness and poor coordination were present in all children. Gross movements were more severely impaired than fine coordination in $72 \%$ of cases. In only $14 \%$ was the reverse true, and both were felt to be equally affected in the remainder. Coordination also appears to improve with time.

Seizures were documented in $50 \%$ of cases, but these took the form of febrile convulsions in approximately half.

\section{CARDIAC FEATURES}

Five patients had structural congenital heart defects. One further patient had unexplained neonatal supraventricular tachycardia which settled on digoxin. Of the five patients with structural anomalies, four had a patent ductus arteriosus (three associated with prematurity at 28, 34, and 35 weeks' gestation) of whom two required surgical closure, one during the neonatal period and the other at 10 years. One child with a PDA is also known to have mild pulmonary stenosis. The fifth child, aged 10 years, has an ASD which requires surgical closure. One further patient developed a pericardial effusion (probably of viral origin) at the age of 10 years, but this resolved with drainage and medical management.

\section{GASTROINTESTINAL SYMPTOMS}

Early feeding difficulties were common and have been documented above. Subsequently, the majority of parents described the appetite $(23 / 26)$ and fluid intake $(26 / 33)$ of their child as markedly greater than other children of com- 


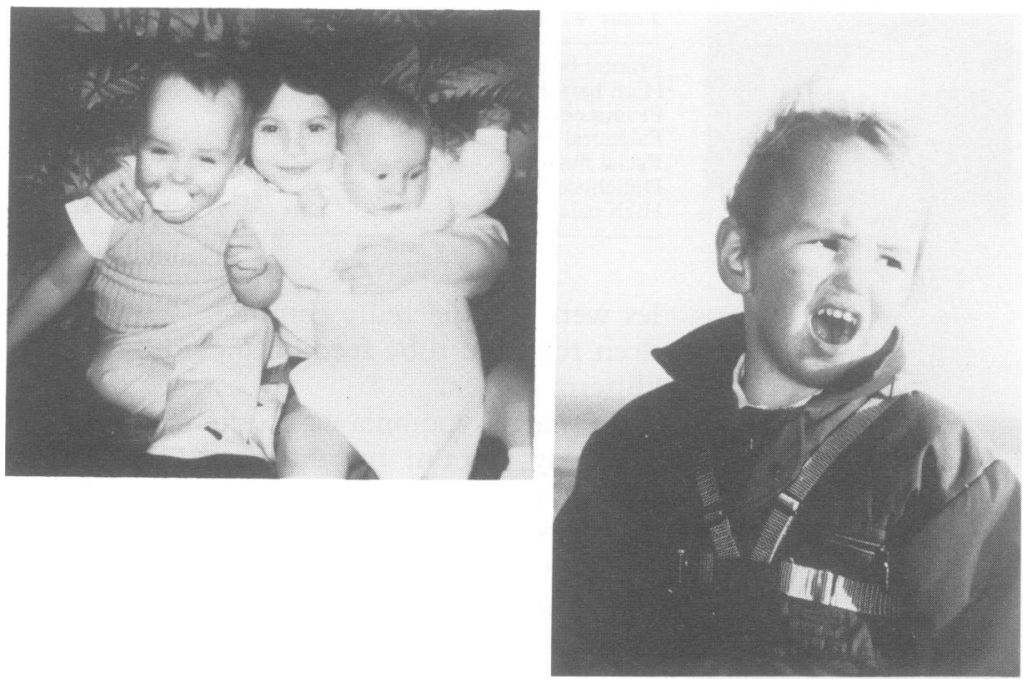

parable age. Constipation was also a common complaint and six children needed specific intervention or investigation (one rectal biopsy, one anal stretch, and four regular medication). Three further children had significant symptoms (two rectal prolapse and one overflow faecal incontinence).

\section{INFECTIOUS ILLNESSES}

Throughout infancy and childhood, frequent upper respiratory tract infections were reported. Otitis media was the commonest and documented in $72 \%$ of children. Conductive hearing loss was an associated finding and

Table 5 Comparison of clinical and absolute hypertelorism.

\begin{tabular}{ll}
\hline Clinical impression of hypertelorism & $95 \%$ \\
Absolute hypertelorism & \\
$>97$ th centile & $61 \%$ \\
$>75$ th $<97$ th centile & $26 \%$ \\
$<75$ th centile & $13 \%$ \\
\hline
\end{tabular}

Table 6 Birth measurements as standard deviations from the mean (group categorised on facial gestalt alone).

\begin{tabular}{|c|c|c|c|}
\hline & Range & Mean & Patients $>+2 S D$ \\
\hline $\begin{array}{l}\text { Group 1 } \\
\text { Birth weight }\end{array}$ & $\begin{array}{l}-1.7 \text { to } \\
+3.8\end{array}$ & $+1 \cdot 0$ & $+6 / 41$ \\
\hline Birth length & $\begin{array}{l}-0.6 \text { to } \\
+9.5\end{array}$ & $+3 \cdot 2$ & $+23 / 27$ \\
\hline Birth OFC & $\begin{array}{l}-1.2 \text { to } \\
+4.6\end{array}$ & $+1 \cdot 8$ & $+12 / 27$ \\
\hline $\begin{array}{l}\text { Group } 2 \\
\text { Birth weight }\end{array}$ & $-1 \cdot 1$ to & +0.8 & $+2 / 16$ \\
\hline Birth length & $\begin{array}{l}-0.6 \text { to } \\
+6.7\end{array}$ & $+2 \cdot 0$ & $+6 / 12$ \\
\hline Birth OFC & $\begin{array}{l}-1.0 \text { to } \\
+4.3\end{array}$ & $+1 \cdot 1$ & $+2 / 12$ \\
\hline $\begin{array}{l}\text { Group } 3 \\
\text { Birth weight }\end{array}$ & $\begin{array}{l}-1.2 \text { to } \\
+3.8\end{array}$ & +0.6 & $+3 / 22$ \\
\hline Birth length & $\begin{array}{l}-0.3 \text { to } \\
+8.2\end{array}$ & $+2 \cdot 3$ & $+7 / 13$ \\
\hline Birth OFC & $\begin{array}{l}-0.7 \text { to } \\
+4.2\end{array}$ & $+1 \cdot 1$ & $+3 / 11$ \\
\hline
\end{tabular}

Table 7 Measurements at diagnosis (mean age 2 years) as standard deviations from the mean (group categorised on facial gestalt alone).

\begin{tabular}{|c|c|c|c|}
\hline & Range & Mean & Patients $>+2 S D$ \\
\hline $\begin{array}{l}\text { Group } 1 \\
\text { Weight }\end{array}$ & $\begin{array}{l}-0.3 \text { to } \\
+6.2\end{array}$ & $+2 \cdot 9$ & $22 / 34$ \\
\hline Height & $\begin{array}{l}-1.1 \text { to } \\
+6.7\end{array}$ & $+3 \cdot 2$ & $29 / 35$ \\
\hline OFC & $\begin{array}{l}+2.0 \text { to } \\
+6.9\end{array}$ & +3.5 & $33 / 33$ \\
\hline $\begin{array}{l}\text { Group } 2 \\
\text { Weight }\end{array}$ & $\begin{array}{l}-0.8 \text { to } \\
+4.0\end{array}$ & $+1 \cdot 1$ & $4 / 15$ \\
\hline Height & $\begin{array}{l}-0.8 \text { to } \\
+3.8\end{array}$ & +1.5 & $5 / 16$ \\
\hline OFC & $\begin{array}{l}-0.1 \text { to } \\
+5 \cdot 0\end{array}$ & $+2 \cdot 7$ & $11 / 15$ \\
\hline $\begin{array}{l}\text { Group } 3 \\
\text { Weight }\end{array}$ & $\begin{array}{l}+0.1 \text { to } \\
+6.7\end{array}$ & $+2 \cdot 8$ & $11 / 19$ \\
\hline Height & $\begin{array}{l}-0.9 \text { to } \\
+4.5\end{array}$ & +1.7 & $7 / 22$ \\
\hline OFC & $\begin{array}{l}+1.5 \text { to } \\
+6.4\end{array}$ & +3.6 & $20 / 22$ \\
\hline
\end{tabular}

resulted in many children undergoing surgical procedures, including tonsillectomy, adenoidectomy, and insertion of grommets. Sensorineural deafness was not identified in the present series.

Microbiologically proven urinary tract infection was identified in eight cases $(20 \%)$. Six had radiological evidence of varying degrees of ureteric reflux and pelvicalyceal dilatation and two further cases required surgical reimplantation of the ureters. Seventy-two percent of cases received no pertussis immunisation, and of these $27 \%$ developed whooping cough on clinical grounds (bacteriological investigation was not performed in all cases).

ORTHOPAEDIC AND SKELETAL FEATURES

Twenty-three of the children had orthopaedic related problems (table 12); pes planus was by far the commonest and required treatment with support or Piedro boots in most cases. Three children were followed for kyphoscoliosis but none required intervention.

Not surprisingly, given their large body size, $30 / 37$ and $31 / 39$ children respectively, had foot and hand lengths above the 97 th centile. Furthermore, when these measurements were plotted against 'height-age', feet and hands still were above the 50th centile in the same proportion of subjects.

Eleven out of 26 patients had suffered fractures but it is difficult to assess if these were more frequent than expected as the children

Table 8 Comparison SD values for height and weight at birth and at diagnosis (mean age 2 years) (group categorised on facial gestalt alone).

\begin{tabular}{lcc}
\hline & $H t>W t$ & $W t>H t$ \\
\hline Group 1 & & \\
At birth* & $25 / 27$ & $1 / 27$ \\
At diagnosis & $21 / 30$ & $9 / 30$ \\
Group 2 & & \\
At birth & $9 / 12$ & $3 / 12$ \\
At diagnosis $\dagger$ & $9 / 15$ & $4 / 15$ \\
Group 3 & & \\
At birth & $12 / 13$ & $1 / 13$ \\
At diagnosis* & $4 / 19$ & $14 / 19$ \\
\hline$* 1$ case $\mathrm{Ht}=\mathrm{Wt}+2$ cases $\mathrm{Ht}=\mathrm{W}_{\mathrm{t}}$ & &
\end{tabular}



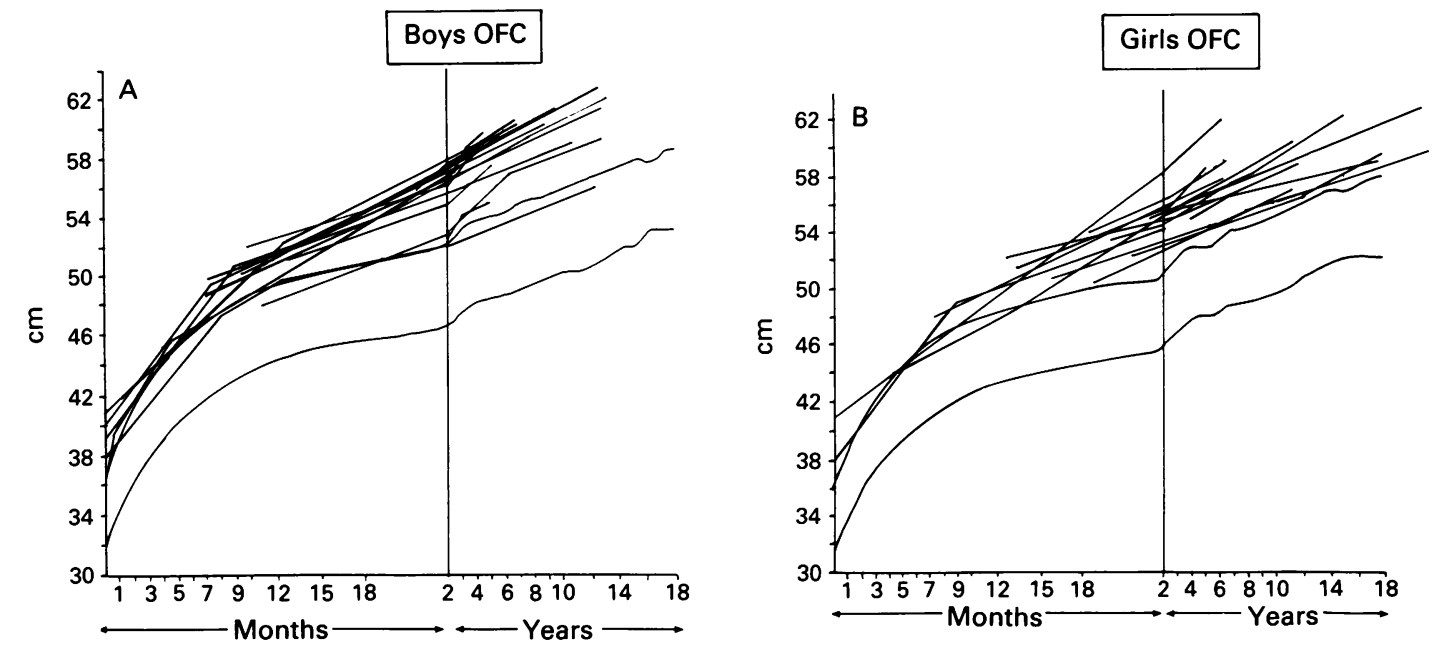

Figure 3 Occipitofrontal circumferences (2nd and 98th centiles marked). (A) First 15 boys in study, (B) first 15 girls in study.
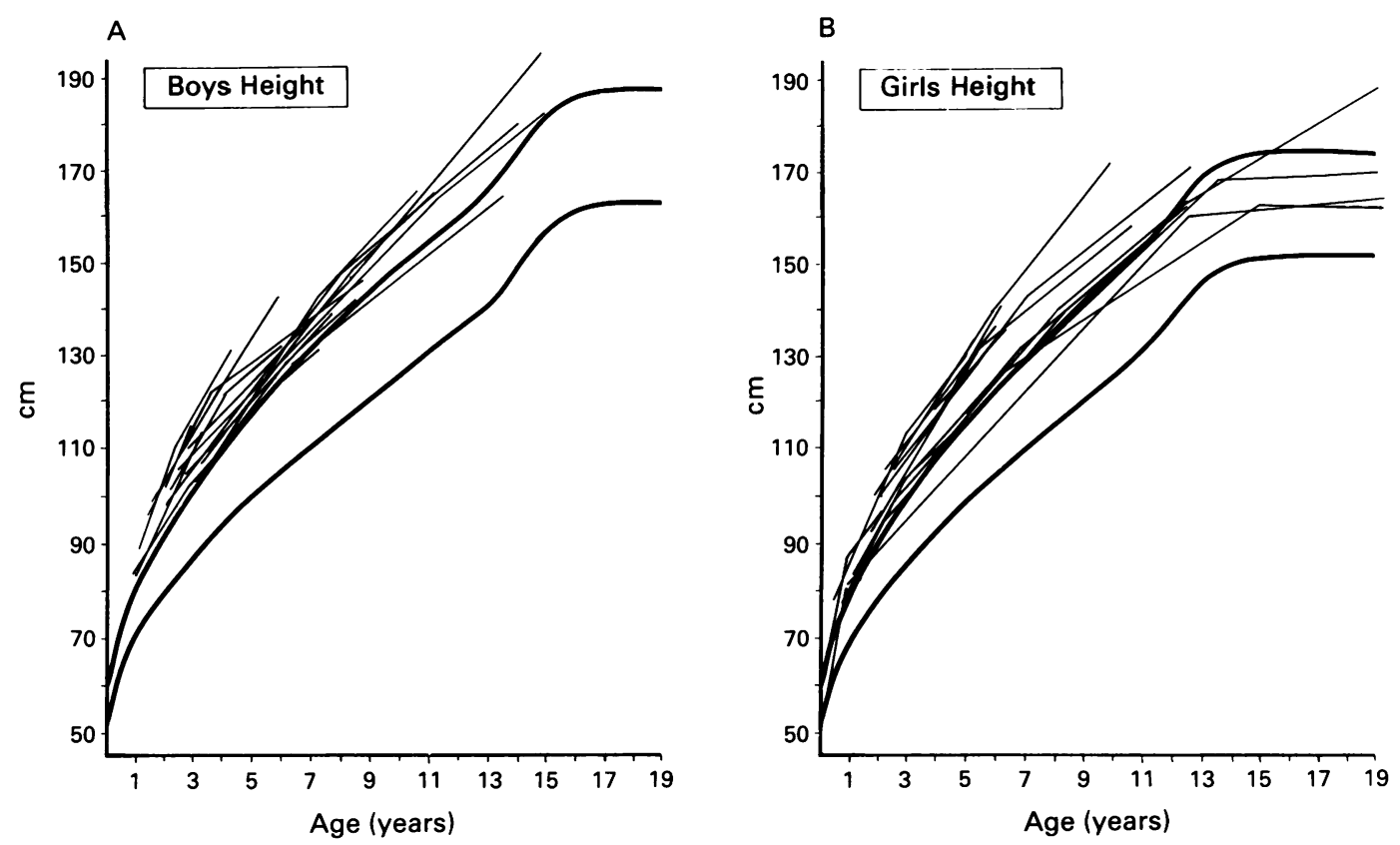

Figure 4 Height charts (3rd and 97th centiles marked). (A) First 15 boys in study, (B) first 15 girls in study.
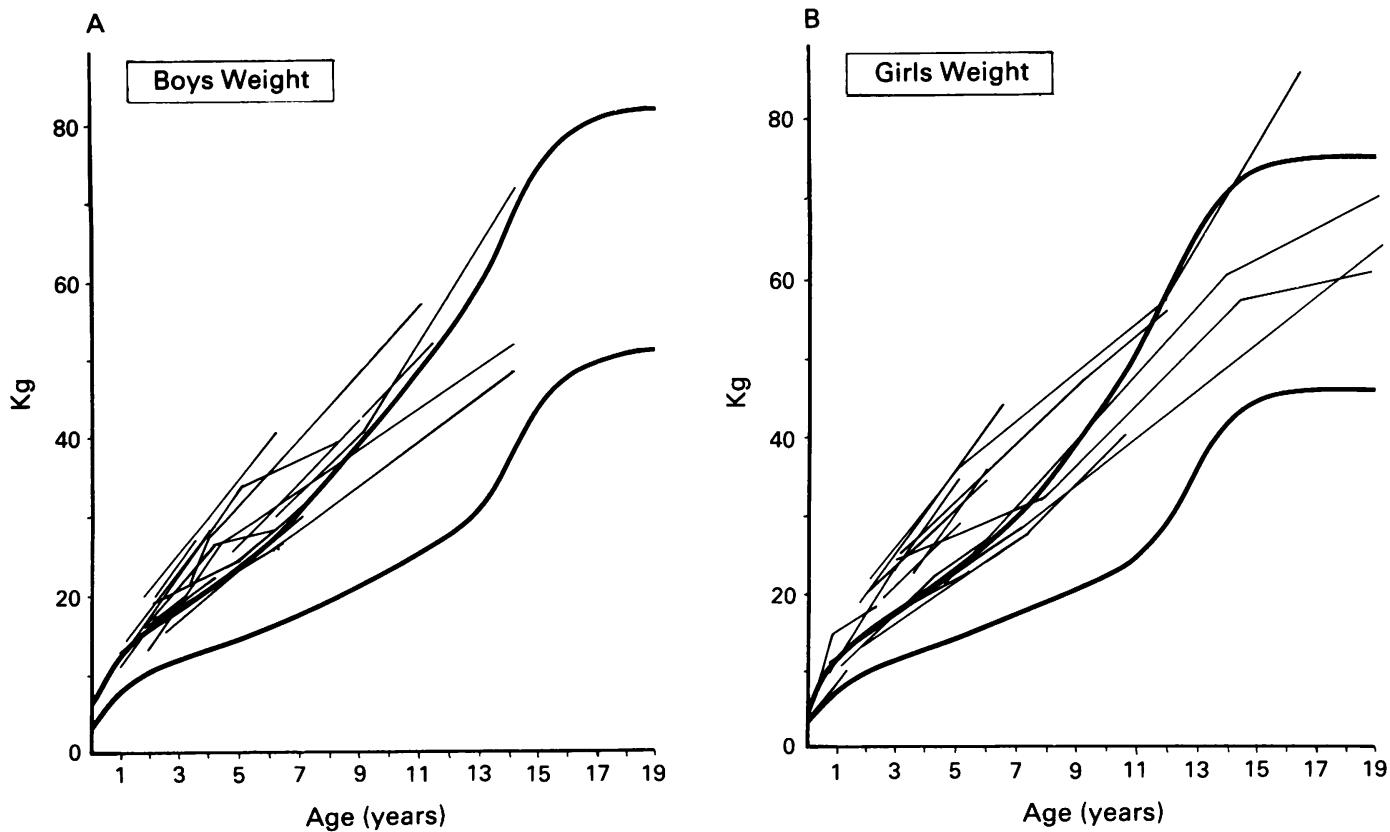

Figure 5 Weight charts (3rd and 97th centiles marked). (A) First 15 boys in study, (B) first 15 girls in study. 
Table 9 Bone ages in 37 cases $(4$ cases $x$ rays unavailable).

\begin{tabular}{lcc}
\hline Centile & No & $\%$ \\
\hline$>90$ th & 31 & 84 \\
$>75$ th-<90th & 3 & 8 \\
$>$ 50th-<75th & 3 & 8 \\
\hline
\end{tabular}

Table 10 School placement.

\begin{tabular}{lr}
\hline Regular class & 10 \\
Regular class with remedial help & 7 \\
Special unit at regular school & 3 \\
Special school & 16 \\
Unknown/preschool & 5 \\
Total & 41 \\
\hline
\end{tabular}

Table 11 Comparison of developmental milestones (mean in months) with later school placement.

\begin{tabular}{lccc}
\hline & $\begin{array}{c}\text { Regular } \\
\text { class }\end{array}$ & $\begin{array}{c}\text { Regular } \\
\text { class }+\end{array}$ & $\begin{array}{c}\text { Sp unit/ } \\
\text { school }\end{array}$ \\
\hline Sitting unsupported & $10 \cdot 8$ & $9 \cdot 3$ & $10 \cdot 4$ \\
Walking unaided & 18.9 & $20 \cdot 6$ & $21 \cdot 1$ \\
2 word sentences & 30.8 & 32.5 & $47 \cdot 3$ \\
\hline
\end{tabular}

Table 12 Orthopaedic problems documented in 23/39 subjects.

\begin{tabular}{lr}
\hline Pes planus & 18 \\
Genu valgus & 6 \\
Valgoid feet & 3 \\
Kyphoscoliosis & 3 \\
Genu varus & 2 \\
Congenital dislocation of hips & 1 \\
\hline
\end{tabular}

are prone to falls because of their coordination problems. However, it should be noted that some of these fractures occurred during later childhood when coordination had improved and in two cases were associated with only minimal trauma.

ECTODERMAL FEATURES

Sparse frontoparietal hair in early childhood was present in $97.5 \%$ of probands. The primary dentition erupted early, $54 \%$ earlier than the 90th centile ${ }^{29}$ and these teeth showed excessive wear and discoloration $(75 \%)$. The finger nails were thin or unusually brittle in $57.5 \%$ of cases.

\section{FAMILY STUDIES}

All available first degree relatives of the probands ( 39 mothers, 30 fathers, 43 out of 47 full sibs, and six out of 23 half sibs) were examined personally by one of the authors (TC). Childhood photographs, where available, were reviewed on all examined and unexamined first degree relatives. In none of these relatives was the diagnosis of Sotos syndrome made.

The mean paternal and maternal ages at the time of delivery of affected subjects were 31.46 and 27.46 years respectively. These were compared to the expected mean parental ages corrected for birth order $(28.56$ for fathers and $26 \cdot 17$ for mothers), using the method described by Bundey et al. ${ }^{30}$ The difference for fathers was significant at a level of $0.02>p>0.01$. For mothers the level of significance was $0.5>p>0.01$.

\section{CYTOGENETIC ANALYSIS}

Chromosome results were available for 30 patients and all were negative for fragile $\mathrm{X}$. In addition several of the remaining subjects had previously been reported as fragile $\mathrm{X}$ negative after local investigation outside the current study. No family exhibited a segregation pattern compatible with $\mathrm{X}$ linked inheritance. One patient (fig 1B, case 23) had an apparently balanced mosaic translocation, $46, X Y / 46$, $\mathrm{XY}, \mathrm{t}(2 ; 4)$ (2qter $\rightarrow 2 \mathrm{p} 15:: 4 \mathrm{p} 14 \rightarrow 4$ pter;4qter $\rightarrow$ 4 p14::2p16.2 $\rightarrow 2$ pter) in two separate blood samples.

\section{METACARPOPHALANGEAL PATTERN PROFILES}

Metacarpophalangeal pattern profiles (MCPP) $)^{31-33}$ were constructed on $64 / 79$ probands; these were assessed by a radiologist (PD, see acknowledgements) without knowledge of group assignment. Many, but not all (30/36), subjects in group 1 showed an MCPP 'typical' of Sotos syndrome. ${ }^{31-33}$ There were both false positive $(10 / 28)$ and negative $(6 / 36)$ assessments, particularly when studying adolescent and adult hand $x$ rays using $Z$ scores (Dijkstra et al, unpublished data). Subsequent analysis using $Q$ scores is reported separately and appears to be a more reliable discriminator. $^{34}$

\section{Differential diagnosis}

Within the differential diagnosis of Sotos syndrome are a number of overgrowth conditions listed in table 1 , but most can be easily excluded on clinical examination. It is interesting to note that the only condition among the well recognised differential diagnoses that was identified in this study were two boys with Weaver syndrome (WS). These patients had been diagnosed as Sotos syndrome by experienced clinicians at 18 and 30 months, but review of infant photographs shows a facial phenotype typical of WS (cases 1 and $2^{35}$ ). The subtlety of the differentiation of Sotos syndrome and WS is discussed in this report. Other conditions recognised in group 3 are listed in table 13 and include six subjects with autosomal dominant macrocephaly and a distinctive phenotype. These cases have been reported separately. ${ }^{36}$

Two patients with chromosomal rearrangements and one case each of Marfan and Prader-Willi syndrome were identified in the 'non-Sotos' group. Twenty-seven of the

\section{Table 13 New diagnoses assigned to group 3 patients.}

Autosomal dominant macrocephaly

Weaver-Smith syndrome

Chromosomal rearrangements

Marfan syndrome

Prader-Willi syndrome 
remaining subjects did not appear to match any previously reported conditions. Within these 27 cases are two sisters with significant developmental delay and characteristic facies with normal bone age and chromosome analyses. Their parents are unaffected and it is likely that they represent a recessive disorder.

\section{Discussion}

The phenotype of developmental delay associated with accelerated growth is probably common and encompasses a number of different disorders. As shown by this study, one of the best known of these conditions, Sotos syndrome, is frequently incorrectly diagnosed. However, there are features present which may enable clinicians to minimise their diagnostic false positive rate. We believe that Sotos syndrome has a very characteristic facial gestalt, especially between the ages of 1 and 6 years and can be distinguished from the facies of subjects in groups 2 and 3.

The consistency with which the 41 patients in group 1 were identified by the three assessors on facial gestalt alone, and the subsequent high degree of concordance when reassessed with knowledge of 'more objective' features (bone age, accelerated growth, and developmental delay), indicate that the patients in group 1 seem to represent a discrete entity. The frequencies of the features used as the major diagnostic criteria in patients categorised to groups 2 and 3 differ from those in group 1 (table 14). Further evidence of misdiagnosis of patients in groups 2 and 3 is provided by the assignment of another diagnosis to almost one-third of cases (table 13).

Each major diagnostic feature in Sotos syndrome, namely growth, bone age, and development, will be discussed separately and their reliability and diagnostic merits considered.

\section{GROWTH}

Prenatal overgrowth is a well recognised feature of Sotos syndrome. The most commonly recorded parameter of growth at birth is weight but, as can be seen from the above data, weight is a poor diagnostic indicator in Sotos syndrome. Our finding that birth length is increased more than weight conforms to the original description. ${ }^{1}$

As illustrated in figs 4 and 5, linear growth is most marked during the first few years of life, after which time the height remains above the 97th centile initially but later has a tendency to fall towards the mean. Of the four cases who do not have increased stature as defined above, one is a premature twin (case 29) whose length

Table 14 Frequencies of diagnostic criteria (defined in methods) in subjects categorised by facial gestalt alone.

\begin{tabular}{lccc}
\hline & $\begin{array}{c}\text { Group } 1 \\
(\%)\end{array}$ & $\begin{array}{c}\text { Group } \\
(\%)\end{array}$ & $\begin{array}{c}\text { Group } 3 \\
(\%)\end{array}$ \\
\hline Height $>97$ th & 95 & 25 & 60 \\
OFC $>97$ th & 98 & 73 & 91 \\
$\begin{array}{l}\text { Bone age }>90 \text { th } \\
\text { Developmental delay }\end{array}$ & 84 & 33 & 38 \\
Ht + bone age + D delay & 100 & 94 & 95 \\
all criteria positive & 77 & 19 & 18 \\
\hline
\end{tabular}

was between the 10th and 25 th centile at birth but is on the 90 th centile at the most recent examination (aged 25 months). She is taller than her male sib (25th to 50th centile) who was the larger at birth. The second subject (case 36) is a 23 year old girl whose height at 16 months and 7 years was +2.3 and $+1.8 \mathrm{SD}$ above the mean respectively and is now on the 50th centile. There are no other intervening measurements available for this patient, who is case 2 in the report of Abraham and Snodgrass. ${ }^{37}$ In the two remaining cases, there is only a single recorded measurement (each above the 97th centile) so they cannot be classified as 'overgrown' by the study criteria. Therefore, 95\% (37/39) of the probands fulfil the stated criteria for increased height. If additional data were available, however, it is likely that the figure would approach $100 \%$.

While it is accepted that longitudinal growth data collected from several sources are less reliable than data recorded by a single person in a standardised fashion, there is nevertheless a common growth trend apparent in the group as a whole. The growth velocity is greater in the prenatal and early childhood periods than in later childhood, and relative obesity (expressed as a ratio of height standard variants to weight standard variants) is uncommon (table 8).

To date, growth data through to adulthood is available on only four females in the study (cases 5, 15, 33, and 36). The final height in three is between the 50th and 97 th centile. The fourth girl (case 33) achieved a final height of $+4.3 \mathrm{SD}$ but had an atypical growth pattern and puberty, and developed a tumour at the age of 23 years.$^{38}$ Data on a further 12 adolescents suggest that girls may have a tendency to early puberty with a final height less increased from the mean, while later puberty in boys is associated with a final height which is likely to be more increased from the mean. ${ }^{39}$

It seems that a birth OFC above the 97th centile would also be a useful diagnostic marker if obtained once perinatal moulding has settled. In those cases where serial neonatal head circumferences are available, there appears to be a dramatic rise in this measurement over the first few weeks of life (fig 3), even in the absence of hydrocephalus.

Head circumference was above the 98th centile in all patients at the time of diagnosis, although in one subject (case 24) it subsequently fell to below the 98 th centile. In this case it is interesting to note that parental head circumferences were below the 50th centile, (mother $52 \mathrm{~cm}=2 \mathrm{nd}$ centile, father $55.6 \mathrm{~cm}=$ 2nd to 50th centile).

\section{BONE AGE}

Although in theory bone age assessments should be reliable, there are many sources of possible error. Firstly, the Greulich and Pyle method $(G+P)$ developed in the $\mathrm{USA}^{40}$ may be less applicable to the British population. Secondly, a given $x$ ray, when assessed with $\mathrm{G}+\mathrm{P}$ standards, will tend to give a more advanced bone age than the same $x$ ray when 
assessed using the TW2 standards. Thirdly, the $\mathrm{G}+\mathrm{P}$ assessments may be less accurate when performed by an inexperienced operator. Finally, the number of patients with 'advanced bone ages' depends on the chosen 'cut off' centile between advanced and normal variation.

In order to provide consistency in the present study, a computer assisted TW2 assessment was performed by a single person (JR). A previous interdepartmental study had shown that this person and another 'blind' assessor produced very similar values using the TW2 method (personal communication, G Roberts). The 90th centile 'cut off' was selected by the authors to indicate an advanced bone age, and on our assessments $84 \%$ of patients were above this centile.

The phenomenon of a relative alteration in the bone ages at different chronological ages is not unexpected and is clearly shown in several patients in this study who have had serial bone age assessments. Four subjects had an earlier bone age reported as normal, but had an advanced bone age on a later $x$ ray taken during the study.

Timing of tooth eruption relied on parental recall and therefore was less objective than bone age. However, the reported frequency of early primary tooth eruption ( $>90$ th $\left.^{\text {centile }}{ }^{29}\right)$ was $54 \%$.

\section{DEVELOPMENTAL DELAY AND NEUROLOGICAL FEATURES}

Earlier reports of frequent and severe mental handicap in Sotos syndrome ${ }^{4142}$ are now generally considered as overly pessimistic and over simplified. ${ }^{43-45}$ Our initial study protocol did not include formal developmental assessments, but DQ and IQ values available for 23 patients (range 40-129, mean 78) are similar to those quoted by Smith. ${ }^{46}$ Our study figure is probably an underestimate of ability as 10 of the 17 children attending regular school have not been formally assessed and were therefore excluded from the calculations of mean and range above. Early developmental assessments rely heavily on the timing of acquisition of specific verbal and motor skills which appear to be particularly delayed in Sotos syndrome. The fact that eight out of 10 children with serial recorded assessments showed improvement with time would support our belief that early childhood assessments may also be overly pessimistic. It is likely that hypotonia in these children retards acquisition of verbal and motor skills, and also possibly coordination. The tendency for tone to increase with age may explain some of the improvement in developmental assessments. Nearly all children, whether above or below average intelligence, had greater difficulty with numeracy than literacy.

The lack of correlation between the degrees of delay of early motor and verbal milestones, and subsequent IQ scores and school placement (table 11) is further evidence of their limited prognostic value. However, it must be kept in mind that other factors such as beha- vioural difficulties and local education provision may affect school placement.

For many parents the major problems relate to behavioural difficulties. In early childhood, temper trantrums were very common and were difficult to manage because of the child's size and strength. 'Overgrowth' gives the children the appearance of being older and therefore their behaviour is commonly perceived as 'unacceptable' by relatives and social contacts. Parents found this judgmental attitude particularly upsetting. Temper tantrums were frequently associated with aggressive behaviour, often directed against parents or sibs. These features may well represent a response born out of frustration because of communication difficulties or inability to compete on intellectual terms, rather than an innate feature of the syndrome.

Persistent immaturity in all aspects was seen right through into adulthood. An example of this immaturity in the area of social skills was evident from the distress and delay seen in achieving separation from parents. ${ }^{47}$ The immaturity created difficulty in socialising with peer groups especially as the children were perceived, by them, as different in size and appearance. Anecdotal reports suggest that many of these features improve in adolescence and teenage years when greater maturity, intellectual ability, and more 'regular' stature develop. In fact several teenagers in the study were described as placid but very good socialisers. It is hoped that the continuing longitudinal study using questionnaires and formal interviews will clarify and quantify these fascinating, but complex, behavioural and intellectual patterns.

\section{FAMILY STUDIES}

Although most cases of Sotos syndrome are sporadic, autosomal dominant pedigrees have been reported. ${ }^{48-54} \mathrm{We}$ are also aware of two unreported families, outside our study, where the probable diagnosis of Sotos syndrome is segregating in an autosomal dominant fashion. On reviewing published reports of familial cases of Sotos syndrome, very few provide sufficient data to meet the diagnostic criteria advocated in this study, the reports by Zonana et $a l^{49}$ and Winship ${ }^{53}$ and our personal communication being the exceptions. Again lack of adequate data is a criticism of some purported autosomal recessive cases, ${ }^{556}$ with the possible exception of the two boys described by Boman and Nilson. ${ }^{57}$ Even in this latter report the data provided on the parents make it difficult to exclude vertical transmission, and germinal mosaicism cannot be ruled out. Most clinicians accept that the family reported by Nevo et al ${ }^{58}$ represents a separate condition.

The fact that in our study 39 of the 79 patients $(49 \%)$ referred with the diagnosis of Sotos syndrome by experienced paediatricians did not meet our criteria for group 1 provides an indication of the frequency of false positive diagnoses. Six families in the excluded group (group 3) appear to have a separate syndrome of autosomal dominant macrocephaly. ${ }^{36}$ It is 
understandable how syndromes with a similar phenotype, as well as other autosomal dominant conditions which may exhibit overgrowth (for example, neurofibromatosis, basal cell naevus syndrome, and the macrocephaly haemangiomata syndromes), could lead to confusion. We believe that with our study protocol it is unlikely that we would have failed to identify affected relatives, particularly among the sibs, as the 'childhood gestalt' is so distinctive.

A model based on a high mutation rate with reduced reproductive fitness is compatible with our study findings. In group 1 there is a significant increase in paternal age $(0.02>p>0.01)$ but no maternal age effect. Previous studies have produced both confirmatory ${ }^{59}$ and conflicting ${ }^{60}$ data.

There are clinical features over and above intellectual impairment and immaturity which may reduce reproductive fitness. In particular endocrinological abnormalities are suggested by the tendency for delayed puberty in males and precocious puberty in females. The latter has been followed by menstrual irregularities and secondary amenorrhoea in at least two cases within our study. Follow up on study cases over time may provide further information about reproductive fitness.

An alternative model could invoke uniparental disomy (UPD) as one causative mechanism. ${ }^{61}$ UPD has been identified in syndromes with growth and behavioural abnormalities, for example, Prader-Willi syndrome, ${ }^{62}$ Angelman syndrome, ${ }^{63}$ and also Beckwith-Wiedemann syndrome, ${ }^{64}$ the latter occasionally segregating in an autosomal dominant fashion. ${ }^{65}$ Our data could be consistent with some cases of Sotos syndrome being the result of point mutations (associated with increased paternal age) in a dominant paternally expressed gene which has a role in growth regulation. In this model, the maternal allele would be imprinted, and maternal disomy would result in loss of this regulation and hence Sotos syndrome. This postulate is currently under investigation.

Whatever the underlying mechanism, the absence of any affected sibs within the study suggests a reassuringly low recurrence risk.

\section{Conclusions}

This study confirms that Sotos syndrome is a specific disorder of growth and development with characteristic facial changes. Although we have not addressed the problem of heterogeneity, we believe that the absence during childhood of any one of the four features listed in table 14 in a case of suspected Sotos syndrome should raise questions about the validity of the diagnosis; absence of two features makes the diagnosis of Sotos syndrome very doubtful. However, our comments concerning timing and method of assessment need to be kept in mind. Developmental delay is a poor diagnostic marker and subject to considerable ascertainment bias. Features which are uncommon, although not excluding Sotos syndrome, are relative obesity, progressive or severe mental handicap, and a clearly documented family history.

The overall outlook for growth, development, and coordination in Sotos syndrome is rather more encouraging than suggested by previous reports. Behavioural problems, which are one of the most distressing areas for parents, may also improve with time, although some immaturity in adulthood is common.

Finally, we suggest that this protocol of 'blind peer assessment' of cases could provide a useful model for the study of dysmorphic syndromes where there is no diagnostic marker.

The authors would like to thank all the children and parents for their time and help, in particular Mrs B Veitch, a parent and organiser of the Sotos syndrome support group; the paediatricians and general practitioners for allowing us to see patients under their care; Dr P Dijkstra for undertaking the MCPP analysis, J Ribeiro for the bone age assessments; and $\mathrm{Dr} A$ Child for her help at the start of the project. Dr Jo-Anne Finegan and Miss Sue Rutter provided valuable insight and interpretation of the behavioural and developmental ata. Chromosome analysis was undertaken by the Departal data. Cyromosome analysis was undertaken by the Department of Cardiff. The childhood photograph of case 36 is reproduced by cardiff. The childhood photograph of case 36 is reproduced by kind permission of the editor of the Archives of Disease in Childhood; all the remaining photographs and artwork would have been impossible without the help of the Department of Medical Illustration at the University Hospital of Wales and Mr R Oliver who provided the cephalometric diagrams. We are also greatly indebted to Drs D Donnai and E Thompson for scoring almost 500 slides. Dr T R P Cole was supported while
undertaking this work by Action Research.

1 Sotos JF, Dodge PR, Muirhead D, Crawford JD, Talbot NB. Cerebral gigantism in childhood. $N$ Engl $\mathcal{f}$ Med 1964;271:109-16.

2 Schlesinger B. Gigantism (acromegalic in type). Proc $R$ Soc Med 1931;24:1352.

3 Weaver DD, Graham CB, Thomas IT, Smith DW. A new overgrowth syndrome with accelerated skeletal maturation, unusual facies and camptodactyly. $f$ Pediatr $1974 ; 84: 547-52$.

4 Ardinger HA, Hanson JW, Harrod MJE, et al. Further delineation of Weaver syndrome. 7 Pediatr 1985;108:22835.

5 Marshall R, Graham C, Scott C, Smith D. Syndrome of accelerated skeletal maturation and relative failure to thrive: a newly recognised clinical growth disorder. $f$ Pediatr 1971;78:95-101.

6 Fitch $\mathrm{N}$. The syndromes of Marshall and Weaver. $f$ Med Genet 1980;17:174-8.

7 Simpson JL, Landey S, New M, German J. A previously unrecognised X-linked syndrome of dysmorphia. Birth Defects 1975;11:18-24.

8 Behmel A, Plochl E, Rosenkranz W A new X-linked dysplasia gigantism syndrome: follow up in the first family and report on a second Austrian family. $A m \mathcal{F} \mathrm{Med}$ Genet 1988;30:275-85.

9 Ruvalcaba RHA, Myhre S, Smith DW. A syndrome with macroencephaly, intestinal polyposis, and pigmentary penile lesions. Clin Genet 1980;18:413-16.

10 DiLiberti J, D'Agostino AN, Ruvalcaba RHA, Schimschock JR. A new lipid storage myopathy observed in individuals with the Ruvalcaba-Myhre-Smith syndrome. Am F Med Genet 1984;18:164-7.

11 Perlman M, Goldberg GM, Bar-Ziv J, Danovitch G. Renal hamartomas and nephroblastomatosis with fetal gigantism: a familial syndrome. $\mathcal{F}$ Pediatr 1973;83:414-18.

12 Greenberg F, Stein F, Gresik MV. The Perlman familial nephroblastomatosis syndrome. Am $\mathcal{f}$ Med Genet 1986;24:101-10.

13 Beckwith JB. Macroglossia, omphacoele, adrenal cytomegaly, gigantism, and hyperplastic visceromegaly. Birth Defects 1969;5:188-96.

14 Wiedemann HR. Complexe malformif familial avec hernie umbilicale et macroglossia - un "syndrome nouveau"? $\mathcal{f}$ Genet Hum 1964;13:223-33.

15 Sanfilippo SJ, Podosin R, Langer L, Good RA. Mental retardation associated with acid mucopolysacchariduria (heparin sulphate type). $\mathcal{F}$ Pediatr 1963;63:837-8.

16 Wiedemann HR, Burgio GR, Aldenhoff P, Kunze J, Kauf mann HJ, Schirg E. The proteus syndrome: partial mann HJ, Schirg E. The proteus syndrome: partia gigantism of the hands and/or feet, naevi, hemihypertrophy, subcutaneous tumors, macrocephaly or other skull anomalies and possible accelerated growth

Clarke Proteus , Donner Proteus syndrome: an expanded syndrome. Am $\mathrm{f}$ Med

18 Pyeritz RE, McKusick VA. The Marfan syndrome. N Engl F Med 1979;300:772-7.

19 Klinefelter HF Jr, Reifenstein EC Jr, Albright F. Syn drome characterised by gynaecomastia, aspermatogenesis oudigism and increased secretion of follicle secreting hormone. 7 Clin Endocrinol Metab 1942;2:615. 

20 Schinzel A. Trisomy 8 mosaicism syndrome. Helv Paediatr

21 Turner G, Daniel A, Frost M. X-linked mental retardation, macrorchidism, and the $\mathrm{Xq} 27$ fragile site. $\mathcal{f}$ Pediat 1980;96:837-41.

22 Tanner JM. Physical growth and development. In: Forfa JO, Arneil GC, eds. Textbook of paediatrics. London Churchill Livingstone, 1973:278-330.

23 Gairdner D, Pearson J. Revised Gairdner-Pearson growth charts. Arch Dis Child 1985;60:1202.

24 Keen DV, Pearse RG. Birthweight between 14 and 42 weeks gestation. Arch Dis Child 1985;60:440-6.

25 Frankenburg WK, Dodds JB. The Denver developmental screening test. $\mathcal{F}$ Pediatr 1967;71:181-91.

26 Tanner JM, Whitehouse RH, Marshall WA, Healy MJR Goldstein $\mathrm{H}$. Assessment of skeletal maturity and prediction of adult height (TW2 method). London: Academic Press, 1975.

27 Rutter SC, Cole TRP. Psychological characteristics of Sotos syndrome. Dev Med Child Neurol 1991;33:898-902.

28 Ginter DN, Scott CI. Cerebral gigantism. Birth Defects 1991;11:415-22.

29 Lysell L, Magnusson B, Thilander B. Time and order of eruption of primary teeth. A longitudinal study. Odonto Rev 1962;13:217-34.

30 Bundey S, Harrison MJG, Marsden CD. A genetic study of torsion dystonia. $\mathcal{F}$ Med Genet 1975;12:12-18.

31 Butler MG, Meaney FJ, Kittur S, Hersh JH, Hornstein L. Metacarpophalangeal pattern profile analysis in Soto syndrome. Am f Med Genet 1985;20:625-9.

32 Butler MG, Piet F, Dijkstra F, Meaney J, Gale DD Metacarpophalangeal pattern profile analysis in Soto syndrome: a follow-up report on 34 patients. $\mathrm{Am} \mathcal{F} \mathrm{Med}$ Genet 1988;29:143-7.

33 Dijkstra PF. Cerebral gigantism (Sotos syndrome), metacarpophalangeal pattern profiles. Fortschr Rontgenstr 1985;143:183-5.

34 Dijkstra PF, Cole TRP, Oorthuys HWE, Venema HW, Oosting J, Nocker RET. Metacarpophalangeal pattern profile analysis in Sotos and Marfan syndrome. $A m \mathcal{F} M e d$ Genet (in press). 35 Cole TRP, Dennis N, Hughes HE. Weaver syndrome. $f$
Med Genet 1992;29:332-7.

36 Cole TRP, Hughes HE. Autosomal dominant macrocephaly: benign familial macrocephaly or a new syndrome? $A m$ $f$ Med Genet 1991;41:115-24.

37 Abraham J, Snodgrass G. Sotos syndrome of cerebral gigantism. Arch Dis Child 1969;55:203-10.

38 Cole TRP, Hughes HE, Jeffreys $M$, Williams GT, Arnold $\mathrm{M}$. Small cell lung carcinoma in a patient with Sotos syndrome: are genes at $3 \mathrm{p} 21$ involved in both conditions? syndrome: are genes at 3p21

39 Cole TRP, Finegan JA, Rutter S, Hughes HE. Sotos syndrome: the size of the problem. 8th International Congress of Human Genetics (Washington). Am f Hum Genet Suppl 1991;49:A35A.

40 Pyle SI, Waterhouse AM, Greulich WW. A radiographic standard of reference for aging the growing hand and wrist. Chicago: Press of Case Western University (Yearbook

41 Jaeken J, Van Schueren-Lodeweyckx M, Eeckels R. Cerebral gigantism syndrome: a report of 4 cases and review of the literature. $Z$ Kinderheilkd 1972;112:332-46.

42 Dodge PR, Holmes SJ, Sotos JF. Cerebral gigantism. Dev Med Child Neurol 1983;25:248-52.

43 Patterson B, Bloom A, Reese A, Weisskopf B. Psychological aspects of cerebral gigantism. $\mathcal{F}$ Pediatr Psych 1978;3:6-8.

44 Bloom AS, Reese A, Hersh JH, Podruch PE, Weisskopf B,
Dinno N. Cognition in cerebral gigantism; are estimates of mental retardation too high? Dev Behav Pediatr 1983;4:250-2.

45 Bale AE, Drum MA, Parry DM, Mulvhill JJ. Familial Sotos syndrome (cerebral gigantism): craniofacial and psychological characteristics. Am $\mathcal{f}$ Med Genet 1985;20:613-20.

46 Smith DW. Smith's recognizable patterns of human malformation. Philadelphia: Saunders, 1988:128-9.

47 Livingood AB, Borengasser MA. Cerebral gigantism in infancy; implications for psychological and social deinfancy; implications for psychological and social de-
velopment. Child Psychiatr Hum Dev 1981;12:46-53.

48 Hansen FJ, Friis B. Familial occurrence of cerebral gigantism; Sotos syndrome. Acta Paediatr Scand 1976;65:387-

49 Zonana J, Sotos JF, Romsche CA, Fisher DA, Elders MJ, Rimoin DL. Dominant inheritance of cerebral gigantism. f Pediatr 1977;91:251-6.

50 Goumy P, Malpuech G, Gannat M, Menet G. Gigantism cerebral familial: une nouvelle observation à transmission autosomique dominante? Pediatrie 1979;34:249-56.

51 Smith A, Rowlands Farraf J, Silink M, Judzewitsch R. Dominant Sotos syndrome. Arch Dis Child, 1980;55.579.

52 Cramer $\mathrm{H}$, Niederdellman N. Cerebral gigantism associated with jaw cyst basal cell naevoid syndrome in two families. with jaw cyst basal cell naevoid syndrom

53 Winship I. Sotos syndrome - autosomal dominant inheritance substantiated. Clin Genet 1985;28:243-6.

54 Kaneko $H$, Tsukahara $M$, Tachibana $H$, Kurashige $H$, Kuwano A, Kajii T. Congenital heart defects in Sotos sequence. Am f Med Genet 1987;26:569-76.

55 Townes PL, Sheinen AP. Cerebral gigantism (Sotos syndrome). Evidence for recessive inheritance. Pediatr Res 1973;7:349.

56 Gemelli M, Carlo Stella N, Barberio G, Tortorella G, Mami C, De Luca F. Sindrome di Sotos in due fratelli. Minerva Pediatr 1982;34:983-6.

57 Boman H, Nilson D. Sotos syndrome in two brothers. Clin Genet 1980;18:421-7.

58 Nevo S, Zeltzer M, Benderly A, Levy J. Evidence for autosomal recessive inheritance in cerebral gigantism. $f$ Med Genet 1974;11:158-68.

59 Jones KL, Smith DW, Harvey MAS, Hall BD, Quan L. Older paternal age and fresh gene mutation: data on additional disorders. $\mathcal{F}$ Pediatr 1973;86:84-8.

60 Wit JM, Beemer FA, Barth PG, et al. Cerebral gigantism (Sotos syndrome), compiled data on 22 cases. Eur $\mathcal{f}$

61 Clarke A. Genetic imprinting in clinical genetics. In: Monk $\mathbf{M}$, Surani A, eds. Genomic imprinting. (Development suppl.) Cambridge: Company of Biologists Ltd,

62 Nicholls RD, Knoll JHM, Butler MG, Karam S, Lalande $M$. Genetic imprinting suggested by maternal heterodisomy in non-deletion Prader-Willi syndrome. Nature

63 Malcolm S, Nichols M, Clayton-Smith J, et al. Angelman syndrome can result from uniparental paternal isodisomy. Am f Hum Genet 1991;47:A227.

64 Henry I, Bonaiti-Pellie C, Chehenesse V, et al. Uniparental paternal disomy in a cancer-predisposing syndrome. Nature 1991;351:665-7.

65 Pettenati MJ, Haines JL, Higgins RR, Wappner RS, Palmer CG, Weaver DD. Wiedemann-Beckwith syndrome: presentation of clinical and cytogenetic data on 22 new cases and review of the literature. Hum Genet 1986;74:143-54 